\title{
Consórcios Intermunicipais de Saúde: Uma Análise à Luz da Teoria dos Jogos*
}

\author{
Luciana Teixeira ${ }^{* *}$ \\ Maria Cristina Mac Dowell ${ }^{* * *}$ \\ Maurício Bugarin ${ }^{* * * *}$
}

Sumário: 1. Introdução; 2. O Modelo básico; 3. Resolução: modelo 1 - com punição; 4 . Resolução: modelo 2 - sem punição; 5. Extensão: um papel para a natureza; 6 . Outras extensões; 7. Conclusão.

Palavras-chave: saúde; municípios; consórcios.

Código JEL: C72; H72; I18.

O presente estudo analisa a formação e a sustentabilidade políticofinanceira dos Consórcios Intermunicipais de Saúde por meio de um jogo dinâmico de dois períodos com informação imperfeita, no qual dois prefeitos de municípios decidem quanto à adesão e à permanência no consórcio. São analisados dois modelos. No primeiro admite-se a suspensão do atendimento nas instalações do consórcio à sua população do município que abandonar a parceria. Já no segundo, considerando o princípio constitucional que estabelece o acesso universal às ações e serviços de saúde, relaxa-se essa hipótese. O estudo evidencia uma forte tendência à instabilidade da associação no segundo modelo.

The present article studies a new organizational structure in which neighboring health districts in Brazil form a partnership to jointly supply costly specialized health care services. Each district partially funds the organization. Depending on the partnership contract, a free rider problem arises. A district has the incentive to withdraw from the partnership if it can still benefit from its services, especially when political pressures for competing expenditures arise. The main conclusion is that the partnership sustainability is

\footnotetext{
${ }^{*}$ Artigo recebido em nov. 2000 e aprovado em abr. 2002. Os autores agradecem a Mirta Bugarin e Mônica Viegas e aos dois pareceristas anônimos, cujos comentários e sugestões muito contribuíram para o aprimoramento deste artigo. Os autores assumem inteira responsabilidade pelos erros remanescentes.

${ }^{* *}$ Departamento de Economia, Universidade de Brasília. E-mail: luteixe@zaz.com.br

*** Instituto de Pesquisa Econômica Aplicada (IPEA) e Departamento de Economia, Universidade de Brasília. E-mail: macdowel@ipea.gov.br

${ }^{* * * *}$ Departamento de Economia, Universidade de Brasília. E-mail: bugarin@unb.br
} 
strongly influenced by the punishment mechanisms to a defaulting member, the gains from joint provision of health services and the overall economic environment.

\section{Introdução}

O consórcio intermunicipal de saúde é uma iniciativa autônoma de municípios localizados em áreas geográficas contíguas que se associam para gerir e prover conjuntamente serviços especializados e de apoio diagnóstico de maior densidade tecnológica à população das municipalidades participantes. Essas associações constituem uma forma inovadora de gestão do Sistema Único de Saúde (SUS) que a cada dia torna-se mais comum em todo o Brasil, principalmente nas regiões Sul e Sudeste. Em 1999, foram contabilizados pelo Ministério da Saúde 143 consórcios que prestam serviços para mais de 1740 municípios, o que corresponde a cerca de $30 \%$ do total de municípios brasileiros.

Grande parte do financiamento desses consórcios é realizada por meio de transferências diretas ou indiretas de recursos do Sistema Único de Saúde (SUS) aos municípios. A forma específica de transferência de recursos do SUS depende da habilitação dos municípios às diferentes condições de gestão. ${ }^{1}$ Em geral, o financiamento é realizado por meio de uma combinação de três fontes básicas: quotas dos municípios consorciados (definidas segundo critérios populacionais e/ou utilização dos serviços), recursos provenientes diretamente do SUS e recursos provenientes das Secretarias Estaduais de Saúde. Os consórcios intermunicipais de saúde do Paraná, ${ }^{2}$ por exemplo, recebem recursos do Ministério da Saúde por serviços prestados; do estado em forma de materiais, equipamentos, recursos humanos, repasse de medicamentos, pagamento de serviços de vigilância e limpeza e insumos médicohospitalares de enfermagem; e da contribuição voluntária das prefeituras.

São várias as evidências que sugerem que o consorciamento em saúde levou ao aumento de eficiência e de qualidade dos serviços ofertados. ${ }^{3}$ Em municípios

\footnotetext{
${ }^{1}$ Vide a Norma Operacional Básica 01/96 (NOB 01/96) para maiores detalhes sobre as duas formas de gestão municipal: gestão plena da atenção básica de saúde e gestão plena do sistema de saúde.

${ }^{2}$ Revista Divulgação em Saúde para Debate, dez. 96.

${ }^{3}$ No tocante à qualidade, não se encontram indicadores de satisfação dos usuários. Um dos poucos estudos que oferece indicadores sobre satisfação de pacientes, Gontijo et alii (1994), referese ao consórcio de Penápolis, onde ficou comprovada a presença de boas instalações e a ausência de filas para o atendimento de pacientes. Pesquisa de Maria Passos Peixoto (2000) confirma o aumento da oferta de serviços nos consórcios de Penápolis, Amunpar e Teles Pires.
} 
de pequeno porte, a oferta de serviços especializados exige, muitas vezes, escala de produção incompatível com a demanda daquela população. A possibilidade de agregação dos municípios pode, portanto, trazer significativas economias de escala. Além disso, em várias regiões, há concentração de leitos hospitalares nos municípios maiores, como no caso de Penápolis (253 dos 286 leitos disponíveis na região, Gontijo et alii (1994)). O consórcio teria o potencial de reduzir a capacidade ociosa nesses municípios grandes ao disponibilizar leitos aos municípios menores que aderirem à parceria.

Cabe ressaltar que os consórcios facilitam a implementação do sistema de referências (unificação da porta de entrada), isto é, a consulta com especialistas é realizada somente após a indicação do clínico, o que tende a reduzir os custos de atendimento. Essas associações também induzem à padronização dos procedimentos médicos, visto que interligam diferentes unidades de saúde, seja por meio do sistema de referências, seja pelo fato dessas unidades estarem sujeitas a uma mesma instância de controle e avaliação. Ademais, a parceria pode representar um incremento dos gastos locais com saúde, permitindo a ampliação e diversificação da oferta de serviços. ${ }^{4}$

Finalmente, do ponto de vista legal os consórcios são pessoas jurídicas de direito privado, o que permite maior flexibilização administrativa. Nessas instituições a contratação de pessoal é realizada segundo a lógica de mercado com pagamento de salários competitivos aos especialistas. No caso do Consórcio Intermunicipal de Saúde de Penápolis/SP (CISA), existe uma gratificação de 50\% sobre o salário praticado em hospitais públicos e no Consórcio do Alto São Francisco/MG também há uma complementação salarial. Em vários consórcios, existem bônus por produtividade. Esses incentivos tendem a melhorar o desempenho dos profissionais e elevar a qualidade dos serviços oferecidos.

Dadas as vantagens acima expostas supõe-se, neste trabalho, que há consenso de que o consorciamento em saúde deve ser incentivado. ${ }^{5}$

Apesar dos benefícios aos usuários dos serviços e do aumento da resolutividade da rede de saúde, podem haver situações em que os municípios decidam abandonar as parcerias, mesmo que essa atitude vá de encontro aos termos contratuais dos consórcios. A viabilidade dessas instituições a longo prazo depende, portanto, de um equilíbrio tênue: a confiança mútua entre gestores. Considerando a fragilidade das finanças municipais e a complexidade do processo político de construção das

\footnotetext{
${ }^{4}$ Dados apresentados por Ribeiro e Costa (1999) mostram que metade da receita do Consórcio de Penápolis (SP), por exemplo, é oriunda de transferências do SUS e a outra parte das cotas municipais.

${ }^{5}$ No âmbito do Ministério da Saúde, no entanto, ainda não há um consenso sobre o melhor modo de implementação da cooperação regional.
} 
parcerias, a manutenção desse equilíbrio pode ser inviabilizada.

De fato, apesar da esfera municipal ter sido a grande beneficiada pela Constituição de 1988 com a elevação da receita disponível, os municípios continuam apresentando uma grande vulnerabilidade fiscal. Se por um lado, aumentaram as suas fontes de recursos, por outro, o processo de descentralização das funções públicas, principalmente das políticas sociais, tem exercido forte impacto nas finanças desses entes federativos, podendo reduzir o interesse do prefeito de um município em honrar seu compromisso para com o consórcio.

Quanto ao processo político, a percepção, por parte dos prefeitos, de que o usufruto dos serviços e benefícios advindos do consórcio poderia ser parcialmente mantido sem sua adesão financeira (comportamento free rider), pode gerar a quebra do pacto entre as partes e a insolvência da associação. Neste artigo supõe-se que os políticos (prefeitos) têm como um de seus maiores objetivos maximizar sua sobrevivência político-eleitoral. Para tanto, tomam decisões de investimento de forma a maximizar seu apoio popular, representado neste estudo pela utilidade de um eleitor mediano.

O interesse específico do eleitorado, entretanto, irá depender do ambiente econômico. Em nosso modelo, quando os eleitores consideram o ambiente econômico favorável, preferem ações em saúde, que têm grande impacto a médio e longo prazos, mas retorno esperado menor no curto prazo. Por outro lado, quando o ambiente econômico é desfavorável, os eleitores preferem outras ações (políticas) cujos resultados são percebidos no curto prazo. Numa situação de crise econômica com elevado desemprego, por exemplo, um eleitor típico tende a preferir uma cesta básica à possibilidade de fazer um exame de ressonância magnética, cuja probabilidade de vir a ser necessitado é pequena.

Essas considerações tanto de ordem financeira quanto política tornam evidente a vulnerabilidade dos consórcios e a possibilidade de sua dissolução. Quando um município adere ao consórcio, mas torna-se inadimplente, os demais consorciados podem reagir suspendendo ou continuando a permitir o atendimento aos pacientes desse município. No primeiro caso, dizemos que houve punição ao município inadimplente. Sendo assim, o objetivo deste trabalho é analisar se a existência ou não de punição afeta o resultado desse intrincado jogo político, no que tange à formação e à manutenção de consórcios.

Usando o instrumental da teoria dos jogos, são analisados dois modelos distintos. O primeiro modelo mostra que um mecanismo para se evitar a interrupção do fluxo de recursos dos municípios aos consórcios é a suspensão do atendimento à população da municipalidade que estiver em débito com suas obrigações financeiras junto à associação. Esse procedimento é adotado por alguns consórcios como, 
por exemplo, o supracitado Consórcio Intermunicipal de Saúde de Penápolis/SP (CISA). No entanto, essa atitude fere o princípio do SUS de acesso universal aos serviços e atenção integral à população, estabelecido no Art. 196 da Constituição Federal. No segundo modelo, verifica-se que a impossibilidade legal de aplicar punição ao município inadimplente pode levar ao abandono do consórcio por parte de um dos municípios ou até mesmo à sua não-formação.

Pesquisas empíricas sobre a atuação dos consórcios intermunicipais de saúde foram realizadas por equipes do Ministério da Saúde e por pesquisadores da Fundação Oswaldo Cruz. Não é de conhecimento dos autores deste trabalho que, até o momento, haja registros de estudos anteriores que relacionem comportamento estratégico à questão da viabilidade político-financeira de consórcios. Assim, a principal contribuição deste estudo é agregar às pesquisas empíricas já realizadas, aspectos relativos à teoria das parcerias e da competição eleitoral em um modelo formal de teoria dos jogos.

O artigo estrutura-se da seguinte forma. A seção 2 apresenta o modelo básico com a forma extensiva do jogo. A seção 3 fornece a resolução do modelo com punição para o município que abandona o consórcio. A seção 4 apresenta a resolução do modelo quando não há punição à municipalidade inadimplente. A seção 5 estende o modelo original para analisar o que ocorre quando a preferência do eleitorado por ações políticas torna-se fortemente dominante no ambiente econômico desfavorável. A seção 6 apresenta outras extensões ao modelo básico. Finalmente, as conclusões e sugestões de refinamentos para pesquisas futuras encontram-se na seção 7 .

\section{O Modelo Básico}

\subsection{Descrição do jogo}

Para analisar a formação e a sustentabilidade político-financeira dos Consórcios Intermunicipais de Saúde, considera-se um jogo dinâmico de dois períodos $t=$ 1,2 , com informação imperfeita, no qual participam dois jogadores, os prefeitos municipais $j=1,2$.

Em cada período, cada prefeito dispõe de um orçamento $B$ a ser alocado em dois tipos de gastos: gastos em ações de saúde e gastos em outras ações, referidos aqui genericamente por ações políticas. Os gastos em ações políticas são gastos tipicamente locais e, portanto, são efetuados separadamente por cada prefeito em seu município. Por outro lado, os gastos em saúde podem ser potencializados caso os municípios se unam por intermédio de um consórcio intermunicipal de saúde 
(CIS), devido aos benefícios desse tipo de associação, já descritos na introdução.

As decisões estratégicas dos agentes são as seguintes. No primeiro período os prefeitos decidem se formam ou não um CIS. Se decidirem não formar, os gastos de cada município são executados localmente em cada um dos dois períodos, não havendo nenhuma interação entre as populações respectivas, nem externalidades intermunicipais. Assim, cada prefeito $j=1,2$ decide independentemente quanto gastar localmente em saúde e em outras ações, em cada um dos períodos $t=1,2$ : $L_{j t}$ (saúde), $P_{j t}$ (outras).

Caso os prefeitos decidam formar um CIS, cada município contribui com uma quantia $S_{a}$ correspondente a uma taxa de adesão que é usada para os investimentos iniciais do consórcio. O investimento $S_{a}$ exige um prazo de maturação de um período e seu retorno, portanto, é realizado apenas em $t=2$. Feita a transferência do recurso $S_{a}$ para o consórcio, cada prefeito $j$ decide como gastar o restante de seu orçamento $\left(B-S_{a}\right)$ em ações locais de saúde $\left(L_{j 1}\right)$ e outras $\left(P_{j 1}\right)$.

No segundo período os agentes decidem se permanecem no consórcio ou abandonam a instituição. Caso permaneçam, usufruem do ganho do investimento inicial $\left(k S_{a}, k>1\right)$ e transferem recursos $S_{q}$ para a manutenção do consórcio. Esses recursos são potencializados pelo CIS, resultando num retorno $l S_{q}, l>1$ para cada município.

Se um dos municípios tornar-se inadimplente, não pagando a quota $S_{q}$, haverá redução do ganho tecnológico do gasto em saúde nas instalações do consórcio auferido pelo município remanescente, que passará a ser $(l / 2) S_{q}$.

A modelagem aqui introduzida tem por objetivo verificar qual o papel dos incentivos no que diz respeito à decisão do prefeito quanto ao abandono do consórcio após sua formação, assim como o efeito desses incentivos nas decisões de formação dessa instituição. Para tanto, a análise será concentrada em um dos dois jogadores, o prefeito $j=2$, assumindo que o prefeito $j=1$ nunca abandonará o consórcio no segundo período.

Existem duas justificativas para tal simplificação, sendo uma de ordem técnica e a outra de ordem empírica. Do ponto de vista técnico, a permanência de um dos prefeitos no consórcio simplifica a descrição e a resolução do jogo e, ao mesmo tempo, tem o potencial de tornar a parceria mais atraente e segura, para o outro prefeito. Assim, se forem obtidos resultados negativos no que diz respeito à viabilidade da parceria nessas circunstâncias, os resultados tornam-se ainda mais significativos no caso em que é permitido que ambos os prefeitos abandonem a parceria. Do ponto de vista empírico, a assimetria entre os dois municípios reflete o fato de que um deles é considerado município-sede, de forma que todo o investimento inicial é feito nesse município, que preserva a estrutura física do consórcio 
caso o outro município decida abandoná-lo. Na prática, tudo acontece como se o município-sede não tivesse a opção de abandonar o consórcio, sendo sua decisão restrita a continuar ou não atendendo os habitantes do município inadimplente. A seção 6 descreve os efeitos nos equilíbrios do jogo quando essa hipótese é relaxada.

Uma vez tomada a decisão de permanecer ou não no consórcio (pelo prefeito $j=2$ ), cada jogador $j=1,2$ decide como gastar seu orçamento (líquido de possíveis gastos com o consórcio) em ações locais de saúde e outras: $L_{j 2}$ (saúde), $P_{j 2}$ (outras).

Finalmente, os prefeitos derivam utilidade de suas decisões de investimento nos dois períodos, conforme descrito na próxima seção.

\subsection{A utilidade do político}

Considera-se, neste trabalho, que a principal motivação do político é manter-se no poder. Sendo assim, o prefeito destinará recursos do orçamento municipal para gastos que maximizem a sua probabilidade de reeleição. $\mathrm{O}$ modelo supõe que o processo eleitoral ocorre no final do segundo período, que o mandato eleitoral é fixo e que há possibilidade de reeleição.

O impacto da escolha de gastos do prefeito sobre sua probabilidade de reeleição dependerá de como os eleitores valorizam gastos em ações de saúde relativamente a gastos em outras ações. Nos modelos estudados supõe-se que as preferências dos eleitores do município 2 no período $t=1,2$ podem ser descritas pela função do tipo Cobb-Douglas:

$$
U_{2 t}\left(S_{2 t}, P_{2 t}, \alpha\right)=S_{2 t}^{\alpha} P_{2 t}^{(1-\alpha)}
$$

Na expressão acima, o parâmetro $\alpha \in[0,1]$, a ser discutido detalhadamente na seção 2.5 , pode variar de um período a outro, revelando como o ambiente econômico afeta a preferência dos eleitores do município 2 entre ações de saúde $\left(S_{2 t}\right)$ vis-à-vis ações políticas $\left(P_{2 t}\right)$. Observe que o termo $S_{2 t}$ refere-se ao investimento total em ações de saúde, o que envolve tanto o gasto local $\left(L_{2 t}\right)$, quanto os gastos no consórcio, se existirem.

Para simplificar a análise, assume-se que os eleitores do município 1 têm seu interesse voltado exclusivamente para gastos em ações de saúde. Essa hipótese, além de simplificar a análise, tem a vantagem de aumentar o incentivo à formação do consórcio, dados os ganhos tecnológicos já discutidos anteriormente. Assim, os resultados de instabilidade que serão mostrados neste trabalho tornam-se ainda mais 
relevantes caso o município 1 também possa realizar gastos em ações políticas. ${ }^{6}$ Destarte, as preferências desses eleitores, em cada período $t=1,2$ podem ser expressas pela utilidade linear abaixo.

$$
U_{1 t}\left(S_{1 t}\right)=S_{1 t}
$$

Na expressão acima o termo $S_{1 t}$ novamente refere-se ao gasto total em saúde, envolvendo tanto o gasto local $L_{1 t}$ quanto os eventuais gastos no consórcio.

Finalmente, o político $j=1,2$ otimiza sua probabilidade de reeleição ao maximizar a soma $U_{j 1}+U_{j 2}$ das utilidades nos dois períodos, não sendo aplicado nenhum fator de desconto intertemporal. Uma discussão dos efeitos de tal desconto no equilíbrio será apresentada na seção 6 .

\subsection{A restrição orçamentária}

Cada município $j=1,2$ dispõe a cada período $t=1,2$ de um orçamento $B$, a ser alocado entre ações de saúde e outras. Conforme mencionado, o prefeito do município 1 irá despender recursos exclusivamente em ações de saúde, que podem ser realizadas diretamente pelo município $\left(L_{1 t}\right)$ e/ou pelo consórcio. Por sua vez, os recursos direcionados ao consórcio são de dois tipos: para investimentos iniciais $\left(S_{a}\right)$ e para sua manutenção $\left(S_{q}\right)$.

Os gastos em investimentos, realizados no primeiro período, são aqueles revertidos para a compra de equipamentos e melhoria de instalações médicas e, uma vez incorridos, não podem ser recuperados (sunk costs). Essas despesas podem ser entendidas como uma taxa de adesão à associação.

Quando não há formação de consórcio, a restrição orçamentária do município 1 , no período $t=1,2$ é:

$$
L_{1 t} \leq B
$$

\footnotetext{
${ }^{6}$ A seção 6 apresenta uma discussão dos resultados obtidos quando essa hipótese é relaxada.
} 
No entanto, se o consórcio for formado, o município 1 terá que alocar parte de seu orçamento para custear investimentos iniciais da associação. Desta forma, a restrição orçamentária do município 1 será, para $t=1$ :

$$
S_{11}=S_{a}+L_{11} \leq B
$$

O orçamento do município 2, além de ser gasto em ações sociais $\left(S_{2 t}\right)$, pode ser direcionado a ações políticas $\left(P_{2 t}\right)$. Se o político do município 2 decidir não aceitar a proposta do município 1 quanto à formação de consórcio, sua restrição orçamentária no primeiro período tornar-se-á:

$$
S_{21}+P_{21}=L_{21}+P_{21} \leq B
$$

Por outro lado, se o político do município 2 decidir aderir à parceria, sua restrição orçamentária no período 1 será:

$$
S_{21}+P_{21}=S_{a}+L_{21}+P_{21} \leq B
$$

Caso o consórcio seja formado no primeiro período, é estabelecida uma quota de recursos por município para sua manutenção, que deverá ser paga no segundo período. Por hipótese, o município 1 não pode abandonar o consórcio. Portanto, independentemente da decisão do município 2 quanto à permanência ou abandono da parceria, sua restrição orçamentária, no segundo período, será:

$$
S_{12}=S_{q}+L_{12} \leq B
$$

Diferentemente do município 1 , o prefeito do município 2 pode optar por continuar ou sair da associação. Caso decida-se por formar e permanecer consorciado, sua restrição orçamentária, no segundo período, será:

$$
S_{22}+P_{22}=S_{q}+L_{22}+P_{22} \leq B
$$


Quando o político do município 2 escolher aderir à parceria inicialmente, mas, no segundo período, decidir não contribuir financeiramente para sua manutenção, sua restrição orçamentária tornar-se-á:

$$
S_{22}+P_{22}=L_{22}+P_{22} \leq B
$$

\subsection{O retorno tecnológico do consórcio}

Os retornos provenientes dos gastos com ações de saúde realizadas pelos prefeitos são potencializados com a formação de um consórcio. Como descrito na introdução, a oferta de serviços de saúde pelo consórcio gera uma série de ganhos decorrentes de economias de escala, da implementação do sistema de referência, da ampliação e diversificação da oferta de serviços especializados, da padronização dos procedimentos médicos e da existência de incentivos monetários que estimulam o aumento de produtividade dos profissionais de saúde. Assim, cada unidade monetária investida no consórcio garante um retorno maior do que aquele resultante de investimentos em ações locais de saúde.

Define-se $k S_{a}, k>1$, como o retorno proveniente do investimento inicial no consórcio e $l S_{q}, l>1$, como o ganho resultante dos gastos com manutenção. Sendo assim, recursos destinados a ações consorciadas em saúde trarão maior retorno social do que a alocação de igual valor em ações locais de saúde. Esse é o grande atrativo dessa estrutura de pooling de recursos e serviços. No entanto, supõe-se que $l<2$ e $k<2$, de forma que esse retorno é limitado superiormente. Essa limitação terá um efeito importante na decisão dos prefeitos, conforme será visto posteriormente.

A diferença entre o retorno proveniente do investimento inicial e aquele proveniente do gasto com manutenção deve-se ao fato de que os gastos respectivos atendem a diferentes propósitos. Os gastos iniciais são tipicamente gastos com bens de capital, como construção ou ampliação das instalações, aquisição de equipamentos, entre outros. Por outro lado, os gastos no segundo período visam tipicamente cobrir os custos de manutenção do consórcio, como salários, suprimentos, etc.

\subsection{Os estados da natureza}

O modelo incorpora incerteza acerca do ambiente econômico. A importância relativa que os eleitores atribuem às ações sociais em relação às políticas no período $t=1,2$ é modelada pelo parâmetro $\alpha_{t}$ na função-objetivo do município 2. Esse 
parâmetro depende do ambiente econômico ser favorável $\left(\alpha_{t}=f\right)$ ou desfavorável $\left(\alpha_{t}=d\right)$, com $f, d \in[0,1]$ e $f>d$. O ambiente favorável indica, por exemplo, um período em que a população encontra-se em melhor situação financeira e, por isso, pode depositar expectativas em ações públicas de médio e longo prazos, que geralmente são aquelas de maior retorno social (no modelo, considera-se ações em saúde).

Por outro lado, quando o ambiente econômico é desfavorável os eleitores têm uma visão de curto prazo, estando mais preocupados com ações que possam ser rapidamente revertidas em seu benefício. Nesse caso é mais valorizado o ganho hoje do que ações que só apresentem benefícios no futuro, mesmo que possivelmente maiores.

$\mathrm{O}$ valor de $\alpha_{t}$ é realizado a cada período $t=1,2$ e observado pelo prefeito do município 2 no momento de tomar sua decisão no período correspondente. Por simplicidade, supõe-se que, no primeiro período ${ }^{7}, \alpha_{1}=f$. Essa hipótese tem o efeito de tornar o consórcio mais atraente nesse período, tornando ainda mais significativos os resultados a serem derivados neste trabalho.

\subsection{A forma extensiva do jogo}

Por tratar-se de um jogo dinâmico com dois períodos, serão apresentadas uma forma extensiva para o jogo em $t=1$ e duas formas extensivas para o jogo em $t=2$, correspondentes às duas possíveis continuações do jogo.

A figura 1 representa o jogo em $t=1$. O jogo inicia-se no nó $t_{11}$ com o município 1 decidindo se propõe ao município 2 a formação do consórcio. Caso a proposta seja feita, o município 2 decide se a aceita (nó $t_{12}$ ). Se 1 não fizer a proposta ou se 2 não a aceitar, o consórcio não é formado e os jogadores decidem isoladamente quanto investir em saúde e em outras ações (nós $t_{13}, t_{14}, t_{16}, t_{17}$ ). Finalmente, se 2 aceitar a proposta feita por 1, o consórcio se forma, os prefeitos efetuam os pagamentos referentes ao investimento inicial $\left(S_{a}\right)$ e decidem como gastar localmente o restante de seus recursos (nós $t_{15}$ e $t_{18}$ ). As curvas pontilhadas modelam o fato de que existem muitas opções de escolha no nó correspondente, sendo apenas uma escolha genérica apresentada. No nó $t_{13}$ por exemplo, o prefeito 1 pode escolher qualquer valor para $L_{11}$ entre 0 e $B$.

\footnotetext{
${ }^{7}$ Assim, no que se segue, usa-se a notação $\alpha$ para o valor do parâmetro $\alpha_{2}$ no segundo período.
} 
Figura 1

A Forma Extensiva do Jogo no Primeiro Período

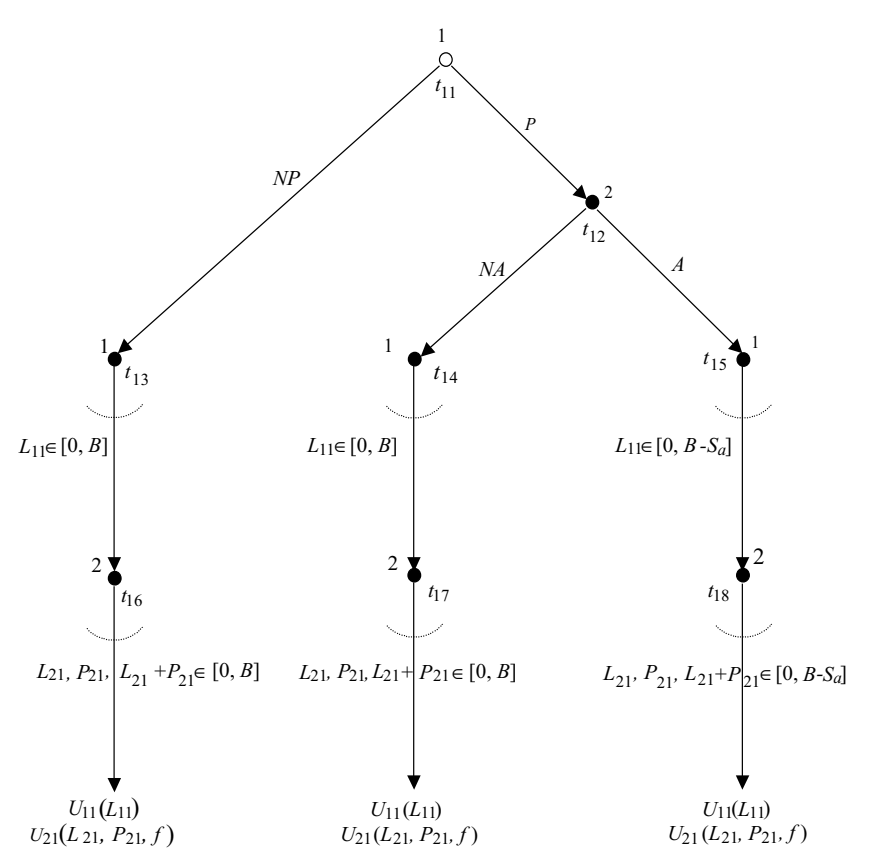

A figura 2 representa o jogo em $t=2$ quando não há formação de consórcio no primeiro período. Nesse caso cada município decide local e independentemente quanto investir em ações de saúde e outras ações, tendo para tanto todo o orçamento $B$ disponível. Neste trabalho, a incerteza com relação ao ambiente econômico é formalizada por meio da introdução de um terceiro jogador: a natureza $(N)$, como é usualmente feito em teoria dos jogos. A probabilidade do estado da natureza ser favorável $(f)$ no segundo período é $\rho$, enquanto a probabilidade de ser desfavorável $(d)$ é $(1-\rho)$. O jogador 2 observa o estado da natureza antes de tomar sua decisão de investimento no segundo período. Como o estado da natureza afeta apenas as preferências dos eleitores do município 2, essa informação é irrelevante para o jogador 1. Por essa razão, a jogada de 1 aparece antes da escolha da natureza. Finalmente, observa-se que, como a decisão de 1 não afeta em nada o jogador 2, não foram utilizados conjuntos de informação não triviais que teriam como único efeito tornar a representação mais carregada. ${ }^{8}$

\footnotetext{
${ }^{8}$ Os conjuntos de informação não-triviais corresponderiam as escolhas simultâneas dos joga-
} 
Figura 2

O Jogo no Segundo Período Sem Formação de Consórcio

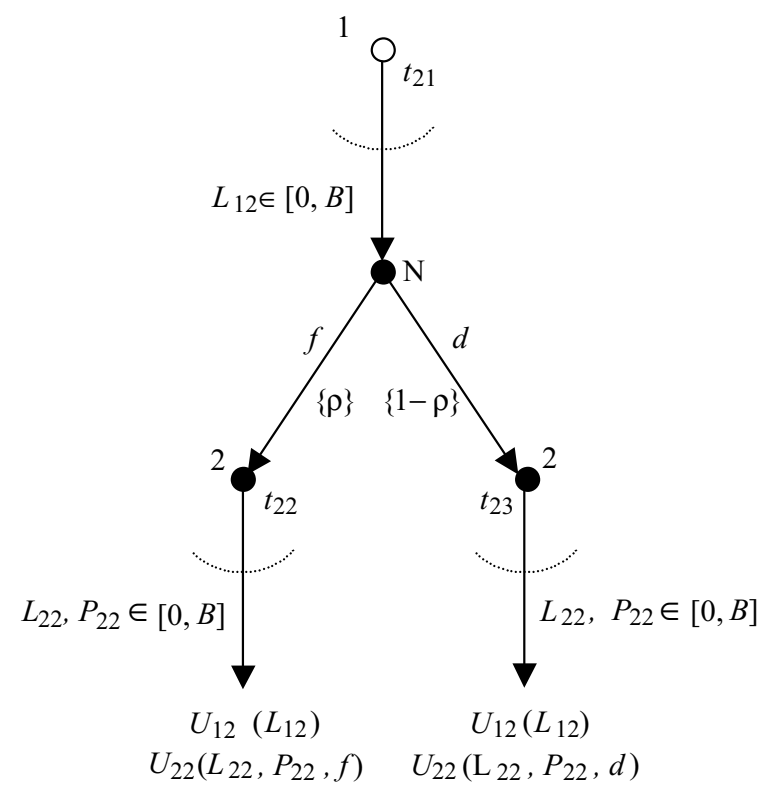

A figura 3 representa a continuação do jogo quando é formado o CIS em $t=1$. Nesse caso o prefeito do município 2 decide se cumpre seu compromisso com a parceria (nó $t_{32}$ ), efetuando o pagamento da quota $S_{q}$, ou torna-se inadimplente, após observar a realização do estado da natureza (nó $t_{31}$ ), ou seja, após verificar a preferência relativa dos eleitores entre ações de saúde e ações políticas ${ }^{9}(\alpha)$. Em seguida, cada município decide independentemente como gastar localmente o orçamento remanescente.

A forma extensiva apresentada aplica-se aos dois modelos que serão estudados neste artigo, por intermédio do parâmetro $\delta$, que pode assumir os valores 0 e 1. Quando $\delta=0$ trata-se do modelo 1, como será visto detalhadamente na próxima seção, no qual inadimplência implica no cancelamento do atendimento

dores 1 e 2 quanto as alocações orçamentárias no segundo período.

${ }^{9}$ Para simplificar a apresentação da forma extensiva incluiu-se apenas uma aresta partindo do nó inicial, rotulada por $\alpha$, que representa as duas possíveis seleções de estado da natureza: $\alpha=$ $f, d$. A probabilidade desses eventos é descrita genericamente por $p_{\alpha}=\rho, 1-\rho$, respectivamente. 
aos residentes do município correspondente. Nesse caso o município 2 deixa de usufruir do retorno tecnológico associado ao consórcio. Por outro lado, o modelo 2 corresponde à situação em que $\delta=1$, na qual os residentes do município inadimplentes mantêm o acesso às instalações do consórcio. Nesse caso, no entanto, o fato de apenas um município contribuir para a manutenção do consórcio reduz o volume de recursos disponíveis, afetando negativamente o retorno tecnológico da instituição.

Figura 3

O Jogo no Segundo Período com Formação de Consórcio

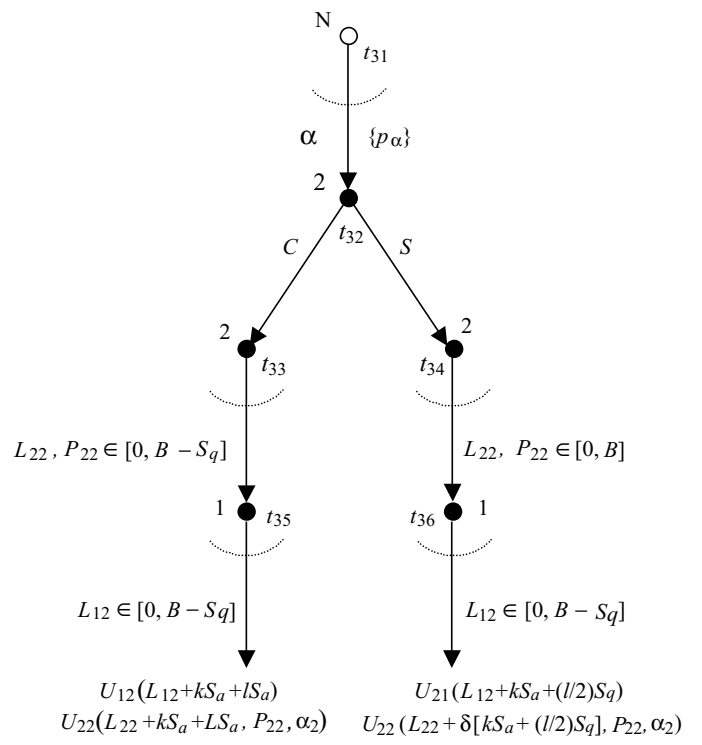

Neste artigo, o efeito da inadimplência é modelado por uma redução do fator tecnológico de $l$ para $l / 2$. Observe que se $l<2$, então o recurso investido no consórcio pelo município 1 em $t=2$ gera menos retorno que aquele investido localmente. Esse fenômeno deve-se ao fato de que o consórcio atende a uma população muito maior - consistindo dos residentes de ambos os municípios do que as instalações locais de saúde. Observe também que o ganho tecnológico associado ao investimento inicial não sofre alteração, uma vez que se trata de um investimento já realizado anteriormente. 


\section{Modelo 1: Com Punição}

Nesse modelo, parte-se da hipótese de que pode ser aplicada punição à população do município que optar por abandonar o consórcio. No município de Penápolis, por exemplo, é suspenso o atendimento nos hospitais consorciados aos cidadãos do município inadimplente.

O jogo é resolvido por indução retroativa. Inicialmente, determina-se os incentivos para a permanência do município 2 no consórcio, resolvendo o jogo na figura 3, em que o consórcio é formado $(F)$ no primeiro período. Para isso, compara-se as suas utilidades para cada uma das possíveis ações: permanecer ou abandonar o consórcio.

No segundo período o prefeito 1 escolherá $L_{12}=B-S_{q}$, independentemente da escolha do prefeito 2 (nós $t_{35}$ e $t_{36}$ ). As utilidades correspondentes para o prefeito 1 são: $U_{12}(C)=U_{12}\left(L_{12}+k S_{a}+l S_{q}\right)=B+k S_{a}+(l-1) S_{q}$, quando 2 decide manterse no consórcio e, $U_{12}(S)=U_{12}\left(L_{12}+k S_{a}+(l / 2) S_{q}\right)=B+k S_{a}+((l / 2)-1) S_{q}$, quando 2 decide abandonar o consórcio.

No nó $t_{33}$, em que o município 2 decide permanecer no consórcio, o problema de maximização do prefeito é, para $\alpha=f, d$,

$$
\left\{\begin{array}{cc}
\max _{L_{22}, P_{22}} & \left(L_{22}+k S_{a}+l S_{q}\right)^{\alpha} P_{22}^{1-\alpha} \\
& L_{22}+S_{q}+P_{22} \leq B
\end{array}\right.
$$

Como a utilidade é estritamente crescente em $L_{22}$ e $P_{22}$, a restrição do problema é ativa. Assim, pela condição de primeira ordem, encontra-se, para $\alpha=f, d$,

$$
L_{22}=\alpha B-(1-\alpha) k S_{a}-[\alpha+(1-\alpha) l] S_{q}
$$

Note que, para que a expressão acima corresponda à solução do problema do prefeito 2, é necessário que os ganhos tecnológicos $k$ e $l$ e as preferências dos eleitores $\alpha$, satisfaçam à condição:

$$
B \geq \frac{1-\alpha}{\alpha} k S_{a}+\left(1+\frac{1-\alpha}{\alpha} l\right) S_{q}
$$

Essa condição pode ser interpretada de duas formas. Por um lado, a taxa de adesão $S_{a}$ e a quota de manutenção $S_{q}$ não podem ser significativamente elevadas em relação ao orçamento municipal total. ${ }^{10}$ Por outro lado, o peso que os eleitores

\footnotetext{
${ }^{10}$ Os 26 municípios do Estado de Minas Gerais que formam o Consórcio do Alto São Francisco destinam exatos $2 \%$ do Fundo de Participação dos Municípios (FPM) para a manutenção da estrutura administrativa do Consórcio (Paulics, 2000).
} 
atribuem às ações sociais $(\alpha)$ em comparação com as ações políticas não pode ser demasiadamente pequeno.

A condição (HIS), chamada neste trabalho de "Hipótese de Investimento em Saúde" é suposta verdadeira nesta seção. Essa condição faz com que o prefeito 2 sempre queira investir localmente em saúde no segundo período, independentemente da realização do estado da natureza. Destarte, o papel da incerteza fica reduzido nesta primeira parte do trabalho. Uma discussão cuidadosa sobre os resultados do jogo quando a hipótese (HIS) não é satisfeita é apresentada na seção 5 .

Substituindo a expressão (1) na função de utilidade do prefeito 2, tem-se que:

$$
U_{22}(C, \alpha)=\alpha^{\alpha}(1-\alpha)^{(1-\alpha)}\left[B+k S_{a}+(l-1) S_{q}\right]
$$

No nó $t_{34}$, em que o município 2 decide abandonar o consórcio $(S)$, o problema de maximização é, para $\alpha=f, d$,

$$
\begin{cases}\max _{L_{22}, P_{22}} & L_{22}^{\alpha} P_{22}^{1-\alpha} \\ & L_{22}+P_{22} \leq B\end{cases}
$$

Resolvendo o problema, obtém-se a solução $L_{22}=\alpha B$ e a seguinte expressão para a função utilidade do prefeito:

$$
U_{22}(S, \alpha)=\left(L_{22}\right)^{\alpha}\left(B-L_{22}\right)^{(1-\alpha)}=\alpha^{\alpha}(1-\alpha)^{(1-\alpha)} B
$$

Comparando-se a utilidade dos prefeitos quando o município permanece consorciado (2) com a utilidade resultante do abandono do consórcio (3), chega-se à conclusão de que a possibilidade de punição é suficiente para garantir a manutenção do consórcio, uma vez constituído, pois: $k, l>1 \Rightarrow B+k S_{a}+(l-1) S_{q}>B$. Assim, qualquer que seja o estado realizado da natureza, o município 2 escolherá continuar $(C)$ no nó $t_{32}$.

A resolução do jogo na figura 2 é imediata. Nesse caso, o consórcio não é formado no primeiro período $(N F)$. O município 1 escolherá $L_{12}=B$ e sua utilidade resultante será $U_{12}(N F)=B$. Por outro lado, no estado da natureza $\alpha$ o município 2 obterá utilidade $U_{22}(N F, \alpha)=\alpha^{\alpha}(1-\alpha)^{(1-\alpha)} B$.

A próxima etapa consiste em determinar os incentivos para a formação de consórcios, correspondendo ao jogo na figura 1. Se o consórcio for formado $(F)$, as utilidades dos municípios 1 e 2 no primeiro período, respectivamente, são:

$$
U_{11}(F)=B-S_{a} \text { e } U_{21}(F)=f^{f}(1-f)^{(1-f)}\left(B-S_{a}\right)
$$


Caso o município 2 resolva não aderir à parceria, ou o município 1 decida não fazer a proposta, as utilidades dos municípios 1 e 2 no primeiro período são, respectivamente:

$$
U_{11}(N F)=B \text { e } U_{21}(N F)=f^{f}(1-f)^{(1-f)} B
$$

Por indução retroativa concluiu-se que no caso em que o consórcio é formado, o município 2 permanecerá consorciado no segundo período. Assim, o payoff resultante da maximização das utilidades do prefeito 1 no primeiro e segundo períodos quando o CIS é formado é:

$U_{1}(F)=U_{11}(F)+U_{12}(C)=B-S_{a}+B+k S_{a}+(l-1) S_{q}=2 B+(k-1) S_{a}+(l-1) S_{q}$

Por outro lado, quando o consórcio não é formado, a utilidade resultante do prefeito 1 nos dois períodos é:

$$
U_{1}(N F)=U_{11}(N F)+U_{12}(N F)=B+B=2 B
$$

Comparando-se as utilidades (4) e (5), conclui-se que o prefeito 1 irá propor a formação da associação.

Com relação ao primeiro período, se o prefeito receber a oferta de formação e recusá-la, sua utilidade esperada no segundo período será $\Theta B$, em que, $\Theta=$ $\rho f^{f}(1-f)^{(1-f)}+(1-\rho) d^{d}(1-d)^{(1-d)}$. Observe que o prefeito 2 calcula sua utilidade esperada, pois no momento de decidir entre aceitar ou não a oferta, ele não sabe ao certo qual será a predisposição de seus eleitores quanto aos gastos em saúde em $t=2$, ou seja desconhece o estado da natureza no segundo período.

Assim, sua utilidade esperada nos dois períodos será:

$U_{2}(N F)=f^{f}(1-f)^{(1-f)} B+\theta B=\left[(1+\rho) f^{f}(1-f)^{(1-f)}+(1-\rho) d^{d}(1-d)^{(1-d)}\right] B$

Por outro lado, caso aceite a proposta, sua utilidade esperada no segundo período será $\Theta\left[B+(l-1) S_{q}+k S_{a}\right]$. Assim, caso aceite a proposta, sua utilidade esperada nos dois períodos será:

$$
U_{2}(F)=f^{f}(1-f)^{(1-f)}\left(B-S_{a}\right)+\left(B+(l-1) S_{q}+k S_{a}\right)
$$

Comparando as expressões (6) e (7) conclui-se que o prefeito 2 aceitará a proposta de consorciamento se e somente se: 
$\left.\theta(l-1) S_{q}+\left[k(1-\rho) d^{d}(1-d)^{(1-d)}+(k \rho-1) f^{f}(1-f)^{(1-f}\right)^{(1-f)}\right] S_{a} \geq 0$

A condição (8) será satisfeita desde que pelo menos uma das condições abaixo seja satisfeita:

- O ganho tecnológico com o investimento inicial, $k$, é suficientemente elevado.

- A probabilidade do estado da natureza ser favorável, $\rho$, é suficientemente grande.

- O ganho tecnológico com a quota de manutenção, $l$, é suficientemente elevado.

- A cota de manutenção, $S_{q}$, é suficientemente grande com relação à quota de adesão, $S_{a}$.

As condições (1) e (2) garantem que $k \rho-1>0$, de forma que todos os termos à direita são positivos. Já as condições (3) e (4) garantem que mesmo que isso não ocorra, o primeiro termo domina o segundo. Neste artigo assume-se que alguma das condições acima é satisfeita, de forma que na única solução por indução retroativa do jogo, o CIS é formado e mantido.

\section{Conclusão do Modelo 1}

Desde que os gastos $S_{a}$ e $S_{q}$ representem pequena parcela do orçamento municipal, a importância atribuída pelos eleitores às ações de saúde (em relação às ações políticas) não seja demasiadamente reduzida e/ou a probabilidade do estado favorável da natureza não seja demasiadamente baixa, o ganho tecnológico é suficiente para garantir a formação e manutenção do consórcio. No entanto, para isso é fundamental que as associações possam punir aqueles membros inadimplentes bloqueando o acesso da população desses municípios aos serviços de saúde do consórcio.

\section{Modelo 2: Sem Punição}

Nesse modelo, supõe-se que não é possível punir o município que abandonar o consórcio, visto que, para os serviços de saúde financiados pelo SUS, é vedado constitucionalmente discriminar entre os cidadãos. Não se pode deixar de atender 
em hospital conveniado um cidadão necessitado de assistência médica, mesmo que o município de origem dessa pessoa não contribua financeiramente para a manutenção da instituição.

Este modelo corresponde ao valor 1 do parâmetro $\delta$ na forma extensiva apresentada na figura 3. Não há modificação nas outras figuras. Assim como no modelo anterior, o jogo é resolvido por indução retroativa, não havendo alteração na resolução do jogo apresentado na figura 2.

Considere o jogo da figura 3. O prefeito 2, se optar por abandonar o consórcio, deixará de pagar sua quota ou taxa de manutenção $\left(S_{q}\right)$. No entanto, sua população não perderá acesso às instalações do consórcio. Dessa forma, o político poderá destinar maior parcela de seu orçamento para atividades políticas. Os recursos despendidos com a taxa de adesão $\left(S_{a}\right)$, no entanto, não são recuperados.

A diferença entre esse modelo e o modelo com punição, resume-se ao fato de que as funções de utilidade do prefeito que abandonar o consórcio perdem apenas parte do retorno $l S_{q}$. O município 2 deixa de contribuir financeiramente para a manutenção do consórcio, mas como não há punição, ainda se beneficia dos gastos realizados pelo outro município. Isso acontece visto que não é possível restringir o atendimento à população do município inadimplente, como mencionado anteriormente.

Para analisar qual será a decisão do político do município 2 quanto à sua permanência ou abandono do consórcio, procede-se novamente à comparação das utilidades nessas duas situações.

Se o município 2 decide permanecer consorciado, o problema de maximização é idêntico ao modelo 1, sem punição, e portanto a função de utilidade do político será dada pela expressão abaixo.

$$
U_{22}(C, \alpha)=\alpha^{\alpha}(1-\alpha)\left[B+k S_{a}+(l-1) S_{q}\right]
$$

No caso em que o município 2 decide abandonar o consórcio, a função de utilidade do político é distinta daquela analisada no primeiro modelo. O problema de maximização será, para $\alpha=f, d$ :

$$
\left\{\begin{array}{c}
\max _{L_{22}, P_{22}}\left(L_{22}+k S_{a}+\frac{1}{2} S_{q}\right)^{\alpha} P_{22}^{1-\alpha} \\
L_{22}+P_{22} \leq B
\end{array}\right.
$$

O termo $\frac{l}{2} S_{q}$, que aparece na função de utilidade do prefeito do município 2, refere-se aos gastos do município 1 com a manutenção do consórcio. Como supõese que, no caso em que o município 2 decide abandonar a parceria, as instalações 
do consórcio continuam atendendo ao mesmo número de pacientes que anteriormente, mas com apenas metade dos recursos, o ganho tecnológico para ambos os municípios é também reduzido pela metade.

Analogamente ao modelo 1, como a utilidade é estritamente crescente em $L_{22}$ e $P_{22}$, pela condição de primeira ordem tem-se,

$$
L_{22}=\alpha B-(1-\alpha) k S_{a}-(1-\alpha) \frac{l}{2} S_{q}
$$

Substituindo (10) na função utilidade do prefeito 2 obtém-se, para $\alpha=f, d$ :

$$
U_{22}(S, \alpha)=\alpha^{\alpha}(1-\alpha)^{(1-\alpha)}\left(B+k S_{a}+\frac{l}{2} S_{q}\right)
$$

Nesse modelo, considera-se que o ganho tecnológico advindo do investimento em manutenção está no intervalo $1<l<2$ e o ganho tecnológico do investimento inicial continua sendo $k>1$. Comparando-se as utilidades do município 2 quando permanece consorciado (9) e quando abandona a parceria (11), conclui-se que esse município irá abandonar o consórcio.

Quanto aos incentivos para a formação do consórcio, considera-se o jogo na figura 1, e analisa-se mais uma vez os payoffs resultantes para o prefeito 2 das ações formar ou não o consórcio (nó $t_{12}$ ). Caso o município 2 rejeite a parceria com o município $1(N F)$, a sua função de utilidade esperada no segundo período - que é idêntica à utilidade esperada do modelo com punição no caso em que o prefeito do município 2 decide sair do consórcio - é dada por $\Theta B$ em que, como anteriormente, $\Theta=\rho f^{f}(1-f)^{(1-f)}+(1-\rho) d^{d}(1-d)^{(1-d)}$. Similarmente, sua utilidade esperada nos dois períodos será:

$U_{2}(N F)=f^{f}(1-f)^{(1-f)} B+\theta B=\left[(1+\rho) f^{f}(1-f)^{(1-f)}+(1-\rho) d^{d}(1-d)^{(1-d)}\right] B$

Supondo que o município 2 decide participar da parceria mas, no segundo período, resolve abandoná-la, sua utilidade esperada no segundo período será $\Theta\left(B+k S_{a}+(l / 2) S_{q}\right)$ e sua utilidade esperada nos dois períodos será:

$$
U_{2}(S)=f^{f}(1-f)^{(1-f)}\left(B-S_{a}\right)+\Theta\left(B+k S_{a}+(l / 2) S_{q}\right)
$$

Comparando as expressões (12) e (13), conclui-se que será melhor para o prefeito 2 aceitar a proposta do prefeito 1 se e somente se:

$$
\theta(l / 2) S_{q}+\left[k(1-\rho) d^{d}(1-d)^{(1-d)}+(k \rho-1) f^{f}(1-f)^{(1-f)}\right] S_{a} \geq 0
$$


A expressão acima assemelha-se à condição (8) no modelo anterior e é supostamente satisfeita pelas mesmas razões já discutidas anteriormente. Assim, o município 2 tem por estratégia dominante aceitar a oferta do município 1 , formando o consórcio no primeiro período, para depois se tornar inadimplente no segundo período.

Passa-se agora à análise dos incentivos para que o município 1 proponha ou não a formação da associação (nó $t_{11}$ ). Se o prefeito não fizer a proposta de formação do consórcio, sua utilidade, considerando os dois períodos, será:

$$
U_{1}(N F)=B+B=2 B
$$

Por outro lado, por indução retroativa o prefeito do município 1 reconhece que se fizer a proposta $(F)$, o prefeito 2 a aceitará e se tornará inadimplente no segundo

período. Assim, a utilidade do prefeito 1, quando faz a proposta de constituição do consórcio ao município 2 , será:

$U_{1}(F)=B-S_{a}+B+k S_{a}-S_{q}+(l / 2) S_{q}=2 B+(k-1) S_{a}-(1-(l / 2)) S_{q}$

Portanto, o município 1 irá propor a formação do consórcio se:

$$
(k-1) S_{a}-\left(1-\frac{l}{2}\right) S_{q} \geq 0
$$

Assim, se a condição (15) for satisfeita, o município 1 fará a proposta, o município 2 a aceitará e se tornará inadimplente no segundo período: haverá formação mas não sustentabilidade de instituição. Por outro lado, se (15) não for satisfeita, o CIS não será nem formado.

\section{Conclusão do Modelo 2}

Diferentemente do modelo com punição, a decisão do município 1 acerca da proposta de consorciamento depende da magnitude dos gastos $S_{a}$ e $S_{q}$, dos retornos tecnológicos $(k$ e $l)$ resultantes de tais gastos e da perda de eficiência associada ao efeito free rider. Se esses parâmetros forem tais que a condição (15) não seja satisfeita, então o município 1 nem fará a proposta de consorciamento. No entanto, se a condição (15) for válida, o município 1 irá propor a parceria, o município 2 aceitará a proposta e, no segundo período, partindo-se da hipótese de que a condição (14) é satisfeita, irá abandonar o consórcio. 
Como neste modelo não é permitida a aplicação de punição ao governo local inadimplente, o prefeito do município 2 continua a auferir ganhos mesmo quando se decide por abandonar o consórcio. No entanto, esses ganhos são menores do que aqueles obtidos quando resolve permanecer. A inadimplência do município 2 reduz pela metade os recursos disponíveis para manutenção do consórcio, levando à queda da eficiência e qualidade dos serviços, o que, por sua vez, provoca um decréscimo, na mesma proporção, nos ganhos tecnológicos.

Assim, este segundo modelo evidencia a grande fragilidade do CIS, tanto no que diz respeito à sua manutenção, quanto no que diz respeito à sua própria formação.

\section{Um Papel para a Natureza}

Considerou-se, até o momento, que a taxa de adesão ao consórcio $S_{a}$ e a quota de manutenção $S_{q}$ não representam parcela significativa do orçamento municipal total e que a importância que os eleitores atribuem às ações sociais $(\alpha)$ não é demasiadamente pequena em comparação com a relevância arbitrada às ações políticas. Essas restrições asseguram que a condição (5) seja satisfeita, o que produz as soluções encontradas nas seções 3 e 4 para o problema de maximização de utilidade do político. Tal hipótese é relaxada nesta seção, conforme descrito a seguir.

Considere a condição (HIS) rescrita na forma abaixo, em que $\varphi(\alpha)=\frac{1-\alpha}{\alpha}$.

$$
B \geq \varphi(\alpha) k S_{a}+[1+\varphi(\alpha) l] S_{q}
$$

Quando $\alpha$ se aproxima de zero, o valor de $\varphi(\alpha)$ torna-se muito grande $\left(\lim _{\alpha \rightarrow 0^{+}}\right.$ $\varphi(\alpha)=+\infty)$ ). Portanto, é pouco provável que a condição acima seja satisfeita nesse caso. Considerando que $\alpha$ representa o valor relativo atribuído pelos eleitores às ações sociais e que no estado desfavorável da natureza $(\alpha=d)$ o valor desse parâmetro é pequeno, é natural supor que a condição (HIS') não seja satisfeita nesse estado. Assim, o prefeito do município 2 irá se decidir por não despender recurso algum em ações de saúde locais, visto que, com o intuito de garantir sua reeleição, os recursos serão preferencialmente direcionados a ações políticas. Além disso, o prefeito 2 terá renovado incentivo a abandonar o consórcio, uma vez formado.

Por outro lado, quando $\alpha$ se aproxima de um, o valor de $\varphi(\alpha)$ converge para zero $\left(\lim _{\alpha \rightarrow 1^{-}} \varphi(\alpha)=0\right)$. Assim, no estado favorável da natureza $(\alpha=f$, grande), o valor de $\varphi(\alpha)$ será muito pequeno. Nesse caso, a condição anterior será facilmente satisfeita. Sendo assim, assume-se que a condição (HIS') ainda é satisfeita se $\alpha=f$ e o município 2 terá um incentivo a permanecer no consórcio. 
Observa-se que agora o prefeito 2 agirá diferentemente dependendo do estado da natureza, tornando-se inadimplente (para certos valores dos parâmetros) no estado desfavorável, mesmo no modelo em que o município inadimplente é punido com a interrupção do atendimento à sua população. Como existe a perda do investimento inicial nesse caso, o município 2 poderá preferir não aceitar a proposta de formação de consórcio no modelo 1 , se a probabilidade do estado desfavorável for muito elevada.

Já no modelo sem punição, o prefeito 2 continua tendo incentivo a aderir ao consórcio, sendo a decisão do município 1 análoga àquela discutida anteriormente (condição (15)).

Conclui-se pois que, quando a natureza desempenha um papel mais efetivo na definição das preferências do eleitorado, a vulnerabilidade dos consórcios quanto à sua formação e à sua manutenção aumenta. O pacto entre os participantes tornase ainda mais tênue o que sugere a atuação premente do governo federal com o intuito de corrigir a ineficiência causada pelo incentivo adverso do free ride.

\section{Outras Extensões}

Esta seção discute outras cinco extensões alternativas aos modelos básicos apresentados na seção 4 .

\subsection{Formato do jogo no primeiro período}

O modelo básico assume que o município 1 decide primeiro se faz a proposta e, caso afirmativo, o município 2 decide se a aceita ou não. Essa assimetria no comportamento dos jogadores pode ser facilmente corrigida. De fato, um formato alternativo poderia ser aquele em que os dois municípios decidem simultaneamente se fazem ou não a proposta de consorciamento. Nesse caso, o CIS somente seria formado se os dois municípios decidissem simultaneamente fazer a proposta ou, interpretando de uma forma mais natural, se os dois municípios concordassem simultaneamente com a formação da associação.

É imediato concluir pela resolução do modelo que essa alteração não afeta em nada os resultados obtidos, sendo os equilíbrios resultantes essencialmente os mesmos. 


\subsection{Simetria na possibilidade de abandonar o consórcio}

Caso fosse possível para ambos os municípios abandonarem o consórcio sem que nenhum dos dois se beneficiasse dessa decisão, apropriando-se das instalações construídas ou equipadas pela parceria, não haveria nenhuma alteração nos equilíbrios do modelo 1. De fato, a ameaça de exclusão é um instrumento poderoso para estimular o município 1 a permanecer no consórcio, uma vez que este último se interessa exclusivamente em gasto em ações de saúde.

Diferentes equilíbrios podem ocorrer no modelo 2. Nesse caso, o consórcio 1 também pode beneficiar-se com o comportamento free rider, se o município 2 mantiver a instituição funcionando. Assim, existem agora dois possíveis equilíbrios com formação de consórcio: no primeiro, como anteriormente, 2 torna-se inadimplente e 1 mantém a estrutura, enquanto no segundo 1 torna-se inadimplente enquanto 2 mantém a estrutura. Em qualquer desses dois equilíbrios há formação do consórcio, mas não há sustentabilidade. No caso em que o ganho tecnológico não compensa o efeito free-rider, o consórcio não é sequer formado, analogamente ao observado no modelo original.

\subsection{Simetria na função de utilidade dos prefeitos}

Supõe-se agora que ambos os prefeitos se preocupam tanto com ações políticas quanto com ações de saúde, como acontece com o prefeito 2 no modelo original. Mantendo-se a hipótese de que o município 1 não pode abandonar o consórcio, e assumindo que uma condição equivalente a (HIS) também vale para esse município, os mesmos resultados do modelo 1 são mantidos.

No entanto, no modelo 2, o peso do comportamento free rider aumenta para o jogador 1, uma vez que as ações em saúde tornam-se menos importantes para esse prefeito. Assim, aumentam os incentivos para que o prefeito 1 não se interesse pela parceria, uma vez que esta, se formada, será dissolvida no período seguinte.

\subsection{Jogo infinitamente repetido}

Parte-se da hipótese, neste tópico, que uma vez formado o consórcio no período $t=1$, o jogador 2 decide a cada período $t>1$ se permanece na instituição, pagando a quota de manutenção $S_{q t}$, ou se abandona o CIS. Uma vez tomada a decisão de sair, o município 2 não poderá mais retornar à instituição. Nesse caso não há alteração no modelo 1: como a ameaça de negar acesso à população do atendimento nas instalações do CIS é suficiente para manter a parceria, esse incentivo torna-se ainda mais forte quando o município 2 percebe que os ganhos com a associação 
podem se repetir indefinidamente. Assim, não há necessidade de um argumento do tipo "Folk Theorem" nesse contexto.

No modelo 2, o efeito free rider persiste a cada período, de forma que 2 tem maior incentivo em aceitar a formação do CIS para depois abandoná-lo e usufruir de suas instalações. No entanto, o ganho adicional com a formação do consórcio, que era o principal incentivo para que 1 fizesse a proposta, encontra-se agora diluído no tempo e reduzido face às perdas que 1 enfrentará em todos os infinitos períodos restantes. Nesse caso 1 optará por não propor a formação do consórcio.

A análise do modelo 2 torna-se diversa se o município 1 tiver a possibilidade de dissolver o consórcio caso 2 torne-se inadimplente. Se a dissolução for irreversível, sua ameaça pode ser usada para disciplinar o comportamento de 2. Nesse caso, um resultado do tipo "Folk Theorem" garante a existência de um equilíbrio de Nash no jogo repetido segundo o qual o município 1 dissolve a parceria caso 2 torne-se inadimplente (estratégia de gatilho). Nessa situação, a estabilidade do consórcio é mantida; no entanto o referido equilíbrio pode não ser perfeito em subjogos. De fato, se a dissolução do CIS implicar na perda total do investimento inicial, a ameaça pode não ser crível. Para aprofundar esse tipo de análise torna-se fundamental estudar que mecanismos serão usados no momento da dissolução da parceria, uma vez que estes desempenham papel fundamental na credibilidade da estratégia do gatilho. ${ }^{11}$

\subsection{Fator de desconto intertemporal}

Supõe-se que existe um fator de desconto intertemporal, $\mu$, que é aplicado pelos jogadores quando estes analisam, no primeiro período, a utilidade esperada em $t=2$. Nesse caso, o custo de oportunidade de não usar o montante $S_{a}$ logo no primeiro período aumenta, tornando a espera pelo prazo necessário à maturação do investimento inicial mais custosa. Assim, apesar de nada mudar na resolução dos jogos das figuras 2 e 3 , que ocorrem no segundo período, aumentam as chances dos jogadores preferirem não constituir o $C I S$ no primeiro período.

\section{Conclusão das Extensões}

A análise das diferentes formas de se generalizar os modelos estudados anteriormente apontam para a confirmação ou a ampliação da instabilidade na formação ou na manutenção dos consórcios intermunicipais de saúde. Assim, os resultados

\footnotetext{
${ }^{11}$ Vide, a esse respeito, Cramton et alii (1987).
} 
obtidos nas seções anteriores parecem robustos no que diz respeito às extensões consideradas.

\section{Conclusão}

A gestão de saúde por meio de consórcios intermunicipais tem propiciado o aumento da qualidade e da eficiência na oferta desses serviços. Apesar dos aspectos positivos oriundos desse tipo de gestão inovadora do sistema de saúde, nem sempre haverá incentivos para a criação e a manutenção da parceria.

Neste trabalho, as questões concernentes à formação e à sustentabilidade financeira dessas associações foram analisadas por meio da construção de dois modelos. No primeiro, admitiu-se a possibilidade de punição da população do município inadimplente através da proibição do seu atendimento nas instalações médicas do consórcio. Já no segundo modelo, considerou-se que não é possível punir o município que não cumprir com suas obrigações financeiras junto ao consórcio e, nesse caso, sua população continua a ser atendida no hospital.

Utilizando o instrumental oferecido pela teoria dos jogos, a partir da construção de um jogo dinâmico de dois períodos com informação imperfeita, é possível analisar as decisões dos prefeitos dos municípios sobre quais ações serão implementadas. O município 1 pode propor ou não a formação do consórcio, enquanto o município 2 , além de decidir se aceita ou não aderir à parceria, caso aceite tem que escolher entre permanecer ou abandonar a associação.

O prefeito de cada município maximiza sua probabilidade de reeleição, sujeita a uma restrição orçamentária. Os eleitores levam em consideração, na hora de decidir seu voto, o resultado de duas possíveis ações implementadas pelos políticos: sociais ou de saúde, cujos benefícios são percebidos pela população no médio e longo prazos, e politicas, que têm retornos menores, mas no curto prazo. A importância que os eleitores atribuem às ações sociais em relação às ações políticas depende da incerteza com relação ao ambiente econômico que pode ser favorável ou desfavorável.

Considerou-se que os consórcios intermunicipais de saúde acrescentam à função utilidade dos prefeitos ganhos tecnológicos $k$ e $l$ provenientes, respectivamente, do investimento inicial $\left(S_{a}\right)$ realizado no momento da formação da parceria e do investimento direcionado para sua manutenção $\left(S_{q}\right)$. Os gastos $S_{a}$, uma vez incorridos, não podem ser recuperados. Sendo assim, as decisões do político irão depender fundamentalmente desses parâmetros.

A diferença essencial entre o modelo com punição e o modelo sem punição, é que no primeiro, quando o município 2 opta por abandonar a parceria irá perder 
os ganhos tecnológicos do consorciamento. No modelo 2, por outro lado, se o político do segundo município torna-se inadimplente, continua a se beneficiar dos retornos provenientes da parceria. Esses ganhos, entretanto, são menores do que aqueles obtidos quando o prefeito opta por permanecer consorciado, uma vez que os recursos disponíveis para a manutenção das ações do consórcio são somente aqueles provenientes da contribuição do município 1.

No modelo 1, com punição, sob a hipótese de que os gastos $S_{a}$ e $S_{q}$ representam pequena parcela do orçamento municipal, o ganho tecnológico é suficiente para garantir a formação e a manutenção do consórcio. O mecanismo de punição impõe uma restrição forte à saída dos municípios, sugerindo que a insatisfação da população devido à perda dos serviços pode ser muito maior do que os possíveis ganhos advindos do maior gasto com ações políticas.

Quando não há mecanismos de punição para o município que abandona o consórcio (modelo 2), a decisão do município 1 acerca da proposta de associação depende do ganho tecnológico resultante do investimento inicial $\left(S_{a}\right)$. Quando o município 1 propõe a parceria, o político do município 2 irá aceitar a proposta de formar um consórcio se esta for feita pelo município 1 e, no segundo período, irá optar por abandoná-lo. Considerando esse comportamento, o prefeito do município 1 somente proporá a formação do consórcio em situações bem específicas, nas quais o ganho tecnológico com os investimentos iniciais é suficientemente elevado para compensar o comportamento free rider do município 2.

Assim, os resultados dos modelos mostram que a formação e a sustentabilidade financeira dos consórcios intermunicipais de saúde dependem de dois fatores: dos mecanismos de punição introduzidos e dos ganhos tecnológicos. O mecanismo de punição provou ser eficaz no objetivo de forçar a permanência dos municípios no consórcio. No entanto, como foi visto, a suspensão do atendimento à população nos postos e hospitais consorciados e financiados com recursos do SUS é inconstitucional. Já o modelo sem punição pode gerar situações não desejadas. Dependendo do tamanho do retorno tecnológico, o consórcio pode nem mesmo vir a ser formado ou, no caso em que é criado, o município 2 pode optar por abandoná-lo, adotando um comportamento free rider. Nesse caso, a inadimplência de um dos municípios traz dificuldades financeiras ao consórcio e, consequentemente, reduz a qualidade dos serviços oferecidos.

Com o intuito de explorar o impacto que os diferentes estados da natureza podem produzir sobre as decisões do prefeito quanto à formação e à manutenção do consórcio, considerou-se uma situação na qual as ações sociais têm relevância muito reduzida nas preferências dos eleitores. Os resultados obtidos nesse caso, tanto no modelo com punição quanto no modelo sem punição, evidenciaram uma vulnera- 
bilidade ainda maior dos consórcios de saúde. Outras extensões ao modelo básico também confirmaram essa tendência de não-sutentabilidade ou não-formação dos consórcios.

A principal implicação desses resultados é que, para garantir a formação e manutenção de consórcios, é necessário introduzir novos mecanismos de incentivos, principalmente quando a natureza desempenha um papel relevante.

Por meio da criação de modelos simplificados, o presente estudo constitui um primeiro passo para a análise da formação e da sustentabilidade político-financeira dessa forma inovadora de gestão do sistema de saúde. A pesquisa iniciada deve ser estendida em diversas direções. Considerando a inconstitucionalidade dos mecanismos de punição atualmente usados para garantir a manutenção de alguns consórcios, é fundamental estudar que instrumentos alternativos podem ser desenvolvidos para substituir a punição em situações nas quais o ganho tecnológico não é suficiente para garantir a manutenção da parceria. Por meio da teoria de desenhos de mecanismos pode-se analisar os efeitos de um incentivo financeiro aos consórcios, concedido pelo governo federal. Nesse caso, a saída de um dos consorciados poderia resultar na suspensão do incentivo, inibindo assim o comportamento free rider.

Apesar de possivelmente induzir à decisão eficiente de manutenção dos consórcios, esse mecanismo implica em novos gastos para o governo federal, que já enfrenta uma difícil situação fiscal. Um modelo alternativo, que evitaria dispêndio federal, seria o desenho de contratos entre os consorciados, pelos quais os governos estaduais e/ou federal passariam a assumir o papel de reguladores, com vistas a assegurar o repasse de recursos ao consórcio. Esse mecanismo de commitment garantiria a permanência dos consórcios, uma vez formados, mas pode resultar em menor interesse dos municípios em participar da parceria. Um modelo misto, envolvendo o uso dos dois mecanismos acima, pode estimular a formação e a manutenção dos consórcios, reduzindo o nível de commitment, assim como o dispêndio do governo federal, visto que os custos seriam divididos entre as duas esferas de governo.

A análise do papel do Estado como estimulador do consórcio, assim como a extensão do modelo para englobar uma maior heterogeneidade entre os municípios de um consórcio são apresentados aqui como sugestões para pesquisas futuras.

\section{Referências}

Akemann, M. \& Kanczuk, F. (1999). Term limits and term lengths. Série de Seminários Acadêmicos n. 29/99. Brasília: UnB. 
Bertone, A. A. (1996). Consórcios intermunicipais de saúde - uma estratégia rumo à regionalização. Revista Divulgação Em Saúde Para Debate, 16.

Cramton, P., Gibbons, R., \& Klemperer, P. (1987). Dissolving a partnership efficiently. Econometrica, 55(3):615-632.

Ferejohn, J. (1986). Incumbent performance and electoral control. Public Choice, 50:5-25.

Gontijo, L. T., Donnini, O., Ribeiro, J. M., \& Cunha, J. P. P. (1994). Penápolis: Relato de experiência. Espaço para a Saúde, 3(3).

Holmström, B. (1982). Moral hazard in teams. Bell Journal of Economics, 13:324340 .

Ministério da Saúde (1999). Relatório interno. Brasília: MS.

Paulics, V. (2000). 125 dicas — idéias para a ação municipal. São Paulo: Pólis.

Person, T. \& Tabellini, G. (2000). Political Economics: Explaining Economic Policy. MIT Press, Cambridge.

Piola, S. (2000). Antecedentes, organização e processo de descentralização do sistema único de saúde. Brasília: mimeo.

Ribeiro, J. M. \& Costa, N. D. R. (1999). Consórcios municipais no SUS. Texto para Discussão n. 669, Brasília: IPEA.

Sousa, M. D. C. S. \& Ramos, F. S. (1999). Eficiência técnica e retornos de escala na produção de serviços públicos municipais: $\mathrm{O}$ caso do nordeste e do sudeste brasileiros. Revista Brasileira de Economia, 53(4):434-461. 